$\overline{\text { Volume 29, Number } 3 \cdot 2015}$

\title{
Threat Interpretation Bias in Children With Obsessive-Compulsive Disorder: Examining Maternal Influences
}

\author{
Lara J. Farrell, $\mathrm{PhD}$ \\ Donna Hourigan, DPsych (Clin) \\ Allison M. Waters, PhD \\ Mathew R. Harrington, BPsySc \\ School of Applied Psychology and Menzies Health Institute Queensland, \\ Griffith University, Queensland, Australia
}

\begin{abstract}
Obsessive-compulsive disorder (OCD) in children is a chronic and debilitating disorder. Cognitive theories propose that threat biases may play a role in the development and maintenance of various anxiety disorders, including OCD. Although there is a small body of research examining cognitive theories of OCD in samples of children and youth (e.g., Reynolds \& Reeves, 2008), to date, there are no studies that have examined overestimation of threat in children in relation to ambiguous scenarios that may imbue mildly aversive, neutral, and positive interpretations. Children with primary OCD and their mothers ( $n=22$ dyads) and nonclinical children and their mothers $(n=26$ dyads) participated in this study. Children with OCD were less accurate in identifying expected feelings across scenarios and perceived all types of situations as being more difficult compared with nonclinical children; however, after controlling for self-reported anxiety symptoms, there were no group differences. Child groups did not differ on other indices of interpretation bias. Mothers of children with OCD, compared with mothers of nonclinical children, also interpreted all types of situations as more threatening and difficult and were less accurate in identifying appropriate emotions in ambiguous situations that may imbue mildly positive connotations. Results are discussed in terms of the broader literature on interpretation bias in anxious children and youth and implications for future research and practice.
\end{abstract}

Keywords: obsessive-compulsive disorder (OCD); children; threat interpretation bias; ambiguous situations

$\mathrm{T}$

The cognitive-behavioral model of obsessive-compulsive disorder (OCD) is among the most widely accepted accounts of the development, maintenance, and exacerbation of obsessive-compulsive (OC) symptoms (Taylor, Abramowitz, \& McKay, 2007). This theory proposes that obsessions and compulsions arise from dysfunctional appraisals of stimuli and/or intrusive thoughts, leading to distress and an intense urge to neutralize the distress or intrusion via maladaptive avoidance and/or ritualizing behaviors (e.g., Clark \& Purdon, 1993; Rachman, 
1997, 1998; Salkovskis, 1985). In adults, these models have generated a large body of empirical support and have led to the development of effective treatments (see Frost \& Steketee, 2002). The Obsessive Compulsive Cognitions Working Group (OCCWG, 1997, 2005) was formed in an effort to advance this body of research and has focused on six specific dysfunctional belief domains identified as important in OCD, including inflated personal responsibility, overimportance of thought, beliefs about the importance of controlling one's thoughts, overestimation of threat, intolerance for uncertainty, and perfectionism. As a result, the Obsessional Beliefs Questionnaire (OBQ; OCCWG, 2001, 2003, 2005) was developed with the aim to synthesize research methodologies aimed at examining beliefs critically important to the pathogenesis obsessions. Factor analytical studies using the OBQ (OCCWG, 2005) have since generally supported a three-factor solution, which incorporates beliefs reflecting (a) responsibility and threat estimation, (b) perfectionism and intolerance for uncertainty, and (c) importance and control of thoughts. Although there is a wealth of support for these specific cognitive biases among adults, there is limited research investigating the role of these belief domains among children and youth. For example, Reynolds and Reeves (2008) conducted a metareview on studies examining cognitive processes associated with OCD among youth and identified only 11 studies, 4 of which used clinical samples. Although the review found some support for cognitive biases among children and youth, the results were largely mixed and narrowly focused on inflated responsibility bias, metacognitions, and thought-action fusion.

Relative to other belief domains, there has been comparatively less research with OCD samples that has examined the tendency to overestimate threat, also referred to as a threat interpretation bias. Aspects of this bias in anxious individuals (Butler \& Mathews, 1983; Foa \& Kozak, 1986) and those with OCD (Carr, 1974) include the tendency to interpret ambiguous information as threatening and to overestimate the severity and subjective probability of aversive events. For example, Steketee and Frost (1994) demonstrated that individuals with OCD are less likely to take risks and linked this overly cautious behavior to overestimation of threat. Furthermore, Steketee, Frost, and Cohen (1998) demonstrated enhanced threat bias in adult OCD patients compared to healthy control participants and adults with anxiety disorders. Another way in which threat interpretation bias can be expressed is in the tendency to underestimate coping ability in ambiguous situations (Guidano \& Liotti, 1983; McFall \& Wollersheim, 1979). In a study of adults with OCD and nonclinical controls, poorer estimates of coping were predictive of more severe OCD symptoms within the OCD sample (Woods, Frost, \& Steketee, 2002). Given that numerous cognitivebehavioral approaches to treatment have been developed to specifically target this bias in OCD, further research is warranted to investigate the occurrence and nature of this bias among adults and children with OCD (e.g., Bolton et al., 2011; Wilhelm \& Steketee, 2006; Wilhelm et al., 2009).

In terms of child studies, Barrett, Rapee, Dadds, and Ryan (1996) showed that clinically anxious (children without an OCD diagnosis) and oppositional children were more likely to interpret socially and physically ambiguous (albeit mildly aversive) scenarios in a threatening way, compared with nonclinical children. Anxious children also proposed more avoidant strategies to cope, whereas oppositional children preferred more aggressive solutions, compared with nonclinical children. Subsequent studies have supported the findings that anxious children interpret ambiguous situations as more threatening than their nonanxious counterparts (e.g., Bögels, Snieder, \& Kindt, 2003; Bögels \& Zigterman, 2000; Chorpita, Albano, \& Barlow, 1996; Creswell, Schniering, \& Rapee, 2005; Suarez \& Bell-Dolan, 2001; Waters, Craske, Bergman, \& Treanor, 2008). Specifically, anxious children interpreted the ambiguous situations to be significantly more dangerous, anticipated more negative emotion, and reported less confidence in their ability to influence such situations (Bögels \& Zigterman, 2000; Muris, Rapee, Meesters, Schouten, \& Geers, 2003; Waters, Wharton, Zimmer-Gembeck, \& Craske, 2008). Examining these biases in children and youth as well as adults with OCD is important to advance developmentally sensitive models 
of OCD. For example, because a range of putatively neutral situations (e.g., using a public bathroom) and/or ambiguous situations (e.g., stains on a kitchen plate) can become those associated with OCD-specific threat and distress, interpretations of a broad range of situations as threatening could be one mechanism among others that contributes to the interpretation of intrusive thoughts and compulsive behaviors as distressing and anxiety provoking (Rachman, 1998). Moreover, if such biases are found to be enhanced in children with OCD, then they may be therapeutic targets that require greater emphasis in treatment. Although there is emerging evidence for the efficacy of cognitive-focused interventions for children and youth with OCD (e.g., Bolton et al., 2011; T. I. Williams et al., 2010), there is limited empirical data to support the nature of dysfunctional beliefs in childhood OCD, relative to adult cognitive models (Reynolds \& Reeves, 2008; T. I. Williams et al., 2010). Further research into the nature of maladaptive interpretation bias in childhood OCD may provide clarity and confidence in cognitive approaches to augment more traditional and widely evaluated exposure-based behavior therapy for pediatric OCD (i.e., Pediatric OCD Treatment Study Team, 2004).

In keeping with the view that parent factors play a key role in the development and amelioration of anxiety symptoms in children (see Rapee, Schniering, \& Hudson, 2009 for a review), the role of parents' own cognitive biases and anxiety levels and their association with children's cognitive biases and anxiety has also received attention in studies of children with non-OCD anxiety disorders. For example, Creswell et al. (2005) demonstrated that child threat interpretation was correlated with child anxiety levels but that maternal threat interpretation bias was not correlated with maternal anxiety. Moreover, although mother and child anxiety were not correlated, mother and child threat interpretation biases were significantly related. This finding has since been replicated in two subsequent studies (Creswell \& O'Connor, 2006; Creswell, O'Connor, \& Brewin, 2006) albeit with inconsistency and without reference to clinical populations or a control group. Micco and Ehrenreich's (2008) study of 40 anxious and 40 nonclinical children (7-14 years) and their mothers included 9 children with a primary diagnosis of OCD. The anxious group on whole displayed greater threat perception and lower coping expectations in situations identified as threatening ("salient situations"), compared to nonclinical children. Furthermore, mothers of anxious children had comparatively lower expectations for their children's coping, and these expectations predicted children's coping expectations in nonsalient and salient situations and threat perceptions in salient situations. These findings highlight the potential role that parent perceptions and interpretations may play in influencing the development of child interpretations of threat and beliefs about coping.

To date, no study has examined threat interpretation biases among children with OCD and their parents, despite such biases being core cognitive components highlighted by the OCCWG $(1997,2005)$. Research specifically exploring the origins of obsessive beliefs in adults has suggested that maladaptive beliefs may have their origins within a familial-based developmental context. Rector, Cassin, Richter, and Burroughs (2009), for example, found that first-degree relatives of adults with early onset OCD scored significantly higher than controls on both inflated responsibility and overestimation of threat, suggesting a familial-based vulnerability for the development of maladaptive cognitive biases. Therefore, a clearer understanding of the role of these biases among children with OCD, as well as the potential influence of parent biases, will assist in developing more refined and empirically supported treatments. Therefore, the major aim of this study was to extent the current literature on cognitive biases associated with OCD by specifically examining overestimation of threat in children-by using a story-based interpretation task with children with OCD and their mothers, and nonclinical children and their mothers.

One limitation of previous studies assessing threat interpretation bias is that they have used "ambiguous" scenarios, which may involve a mild degree of threat (Kuckertz, Amir, Tobin, \& Najmi, 2013); for example, "you are walking to school and notice you have a funny feeling in 
your tummy" (Barrett et al., 1996). These methodologies leave it unclear as to whether anxious children (including those with OCD) overestimate threat in putatively neutral or ambiguous situations or whether these prior group differences reflect on biases in the appraisal of genuinely threatening (albeit mild) situations (e.g., Buhlmann, McNally, Wilhelm, \& Florin, 2002). Therefore, a secondary aim of this research was to attempt to control for valence and ambiguity by assessing children's perceptions of their cognitive, emotional, and behavioral responses to ambiguous situations that may imbue mildly aversive or mildly positive connotations with those that were ambiguous and neutral in emotional valence.

The first hypothesis of this study was that children with OCD relative to controls would display stronger threat interpretations of ambiguous situations that may be mildly aversive, consistent with prior research to the extent that several of these studies use scenarios that are potentially mildly aversive (e.g., Barrett et al., 1996; Bögels \& Zigterman, 2000); that such a bias might generalize to ambiguous situations that are neutral in emotional valence as expected based on cognitive theories (Beck \& Emery, 1985; Rachman, 1997; Salkovskis, 1985; J. M. Williams, Watts, MacLeod, \& Mathews, 1997). Moreover, if such biases are specific to threat and ambiguous situations, then no group differences would be expected for ambiguous situations that imbue mildly positive emotional valence. Given that children with OCD also frequently experience comorbid anxiety symptoms and anxiety disorders, we further aimed to examine the degree to which interpretation bias might be associated with OCD even after controlling for child-reported anxiety symptoms. We expected that children with OCD would display robust threat biases relative to controls after controlling for anxiety.

Second, it was hypothesized that mothers of children with OCD would display stronger threat interpretation bias in ambiguous situations that may be mildly aversive and neutral compared with mothers of nonclinical children. It was predicted that there would be no differences between mother groups in response to ambiguous situations that may be mildly positive. Finally, based on Creswell et al. (2005), Hypothesis 3 proposed that there would be a positive correlation between the interpretations of children and their mothers in ambiguous-neutral, ambiguousmildly aversive, and ambiguous-mildly positive situations.

\section{Method}

\section{Participants}

Participants included 22 children with a primary diagnosis of OCD (12 male, $M_{\text {age }}=9.73$ years, $S D=1.35$ years $)$ and 26 children not meeting the criteria for any disorder aged 8-12 years ( 14 male, $M_{\text {age }}=9.73$ years, $S D=1.31$ years $)$. Mothers of children with OCD $\left(M_{\text {age }}=40.90\right.$ years, $S D=4.89$ years; missing case $n=1)$ and of nonclinical children $\left(M_{\text {age }}=41.23\right.$ years, $S D=5.60$ years) also participated in the study. For children with OCD, clinician severity ratings of the child's OCD diagnosis is based on the Anxiety Disorders Interview Schedule for DSM-IVParent report (Silverman \& Albano, 1996) ranged from moderate (4) to very severe interference (8). The mean clinician severity rating of $5.95(S D=1.17)$ indicated that this group was experiencing clinically significant interference from their OCD symptoms. The mean score for the Children's Yale-Brown Obsessive-Compulsive Scale's (Scahill et al., 1997) Obsessions Severity scale was $9.62(S D=3.91)$ and for the Compulsions Severity scale was $10.81(S D=3.71)$. Total OCD symptoms were in the moderate range $(M=20.50, S D=7.04)$. In the nonclinical group, the mean Spence Children's Anxiety Scale-Parent Version (Spence, 1998) score was in the nonclinical range $(M=12.34, S D=6.14)$.

The Anxiety Disorders Interview Schedule for DSM-IV-Parent Version (see description in the following text) revealed a high rate of comorbidity with other disorders at the time 
of assessment. Of the group, 20 participants (90.91\%) met criteria for a second diagnosis. The most common secondary diagnosis was generalized anxiety disorder (8), followed by specific phobia (5), pervasive developmental disorders (3), social anxiety disorder (2), separation anxiety disorder (1), and attention deficit hyperactivity disorder (1). In addition, 12 of these 20 children $(54.54 \%)$ met criteria for a third diagnosis. Generalized anxiety disorder was the most commonly reported third diagnosis (4). Other diagnoses included specific phobia (2), social anxiety disorder (2), attention deficit hyperactivity disorder (2), separation anxiety disorder (1), and dysthymia (1). Interestingly, 18 of the 20 participants with OCD had a comorbid anxiety disorder.

\section{Measures}

The Anxiety Disorders Interview Schedule for DSM-IV—Parent Version (ADIS-P; Silverman \& Albano, 1996) is a semistructured clinical interview for the diagnosis of childhood anxiety disorders and related disorders. Clinicians rate each diagnosis on a 9-point scale of severity $(0=n o$ interference, $8=$ severely disabling) providing the clinician severity rating (CSR). The diagnosis with the highest CSR is deemed the principal diagnosis. The ADIS has established sound psychometric properties. It yields excellent retest reliability for combined, parent, and child ratings of anxiety disorders (Silverman, Saavedra, \& Pina, 2001). The ADIS-P interviews were conducted by clinically trained postgraduate research students who were provided initial training and ongoing supervision by the senior author (LJF) of the study. An independent trained interviewer (also a clinically trained postgraduate research student) coded $20 \%$ of all diagnostics interviews and found excellent interrater reliability with primary diagnosis $\kappa=1.0$, secondary diagnosis $\kappa=$ 0.84 , and tertiary diagnosis $\kappa=0.83$ (Farrell, Waters, \& Zimmer-Gembeck, 2012).

Children's Yale-Brown Obsessive-Compulsive Scale (CY-BOCS; Scahill et al., 1997) is a clinician-rated, semistructured interview assessing the severity of OCD symptoms. The CY-BOCS is widely used and provides ratings of severity for obsessions and compulsions across five scales: (a) frequency (i.e., time occupied by symptoms), (b) interference, (c) distress, (d) resistance, and (e) degree of control over symptoms and also provides a total severity score. The CY-BOCS interviews were conducted by clinically trained postgraduate research students who were provided initial training and ongoing supervision by the senior author (LJF) of the study. To establish reliable ratings on the CY-BOCS, interviewers were required to participate in a training workshop on the CY-BOCS (delivered by the first author $[\mathrm{LJF}]$ ), followed by directly observing two interviews, and then being directly observed by a previously deemed "reliable interviewer" for a further interview before administering interviews independently. All CY-BOCS interviews were presented in group supervision whereby consensus ratings on severity were obtained based on incorporating feedback from the interviewer, supervisor, and team. The CY-BOCS has demonstrated reasonable reliability and validity, with good to excellent interrater agreement and high internal consistency for total score of .87 (Scahill et al., 1997).

The Multidimensional Anxiety Scale for Children (MASC; March, 1997) is a 39-item, 4-point Likert self-report screening instrument for assessing anxiety symptoms in children and adolescents aged 8-19 years. The MASC provides a total anxiety disorder index and scores for social anxiety, physical symptoms, harm avoidance, and separation-panic. The psychometric properties of the MASC including the factor structure, reliability, and validity have been found to be satisfactory (March, Parker, Sullivan, Stallings, \& Conners, 1999).

The Spence Children's Anxiety Scale-Parent Version (SCAS-P; Spence, 1998) was completed by all parents in the nonclinical group as an initial screen. The SCAS-P is a 39-item parent report measure of anxiety in children. For children aged 6-11 years, the range for children with anxiety disorders for boys is $31.1(S D=12.9)$ and $33.0(S D=13.5)$ for girls (Nauta et al., 2004). The SCAS-P has demonstrated sound psychometric properties, including satisfactory to excellent 
internal consistency as well as convergent and divergent validity (Nauta et al., 2004). It has good internal consistency (i.e., $\alpha=.89$; Nauta et al., 2004) and convergent validity with the Child Behavior Checklist (Nauta et al., 2004).

The Depression Anxiety Stress Scales (DASS; Lovibond \& Lovibond, 1995) measures selfreported current depression, anxiety, and stress in adults and was completed by mothers in this study. The 21-item version is used in this study. The DASS has a 4-point Likert scale to rate the extent to which symptoms of depression, anxiety, and stress have been experienced over the past week $(0=$ did not apply to me at all, $3=$ applied to me very much or most of the time $)$. The DASS Depression scale correlates (e.g., $r s=0.45-0.66$ ) with other questionnaires and clinical rating measures of anxiety, depression, and negative affect in ways which demonstrate the convergent and discriminant validity of the scales (e.g., Brown, Chorpita, Korotitsch, \& Barlow, 1997). The DASS scales have demonstrated excellent internal consistency (Depression $=.96$, Anxiety $=.92$, Stress $=.95$ ) and sensitivity to treatment effects (e.g., Page, Hooke, \& Morrison, 2007).

The interpretation bias task ${ }^{1}$ included 18 descriptions of situations that children are likely to experience, or be familiar with, as part of everyday life. Previous authors have suggested that ambiguous scenarios used in previous research may in fact be mildly threatening rather than ambiguous/neutral (Bögels \& Zigterman, 2000; Kuckertz et al., 2013), meaning that anxiety-related differences observed in prior studies may be because of the biased evaluation of threat rather than the interpretation of ambiguous/neutral events as threatening. Therefore, this study sought to control for the emotional valence of ambiguous scenarios by devising a set of situations that were ambiguous but may be mildly threatening, and a set of situations that were ambiguous but neutral in emotional valence. Moreover, because previous studies have not included ambiguous situations that may be mildly positive, it is unclear whether clinical children make more threatening interpretations of situations overall than nonclinical children. Thus, inclusion of a set of mildly positive/ambiguous scenarios would clarify if interpretation biases are specific to mildly threatening situations (threat-specific bias), relate to ambiguous situations (interpretation bias), or are elevated for both mildly threatening and positive situations (generalized threat bias).

The child versions of the 18 situations were first piloted with postgraduate psychology students following a workshop on child anxiety and information processing biases to determine that they were reflective of everyday events in children's lives and to obtain an objective assessment of whether the scenarios fell in the expected categories, that is, ambiguous events that potentially have threatening connotations, ambiguous situations that potentially have positive connotations, and ambiguous events that do not convey emotional valence in either direction. ${ }^{2}$ Data from nonclinical children would then provide an indication of the applicability to typically developing children and whether interpretations are biased relative to controls in children with OCD.

The six ambiguous-mildly aversive events were largely adapted from previous studies, particularly Bögels and Zigterman (2000) and Butler and Mathews (1983); for example, It is the middle of the night and you wake up because of a loud bang. Six were ambiguous-mildly positive; for example, It is school holidays and you and your family are going away somewhere new, and six were ambiguous events with neutral emotional connotations; for example, You are helping your mum do some baking and the phone rings.

Responses were obtained with three open and four closed questions. Open questions included "What would you think in the situation," "What would you feel in the situation," and lastly, "What would you do in this situation." Closed questions included participants rating the valence of the situation ("What kind of situation do you think this would be?") on a 5-point Likert scale from positive/good to negative/bad as well as type of emotion experienced "What would you feel if you were in this situation?" and referred to a selection of core emotions. Following this, they rated coping attributions ("How confident are you that you could cope with this situation?") with responses rated on a 5-point Likert scale from not at all confident to very confident, and "If you 
were in this situation how difficult would you find it" rated on a 5-point Likert scale from not at all difficult to very difficult. Open questions were always asked before closed questions to avoid biasing children's open responses.

Two independent coders who were blind to the diagnostic status of the participants coded open response data. One of the coders was a student researcher involved in this study (second author $[\mathrm{DH}]$ ) and the other coder was a Master's trained psychologist who worked in child mental health care. Both coders were trained for consistency by the senior author (LJF) and rated all open responses for both children and mothers. Prior to coding, participant responses were de-identified, and response types (i.e., thoughts, feelings, and coping plans) were provided to coders separately from each other and presented in a different order. This was to ensure that coders did not have access to the other information when coding and therefore could not be influenced in their coding decisions. Reliability procedures followed those described in Bögels, van Dongen, and Muris (2003). Interrater agreement overall ranged between $80 \%$ and $94 \%$ for thoughts, $93 \%$ and $99 \%$ for feelings, and $80 \%$ to $94 \%$ for coping plans. Full procedures for coding are described as a footnote. ${ }^{3}$

\section{Procedure}

Ethical approval for the research was obtained from the Griffith University Ethics Committee. Approval was also received from Catholic Education and a local primary school's principal to recruit nonclinical children. First-year psychology students with children in the appropriate age range were also recruited for the nonclinical group. The ADIS-P was conducted over the telephone with mothers of all nonclinical children to confirm that children did not have a diagnosis of OCD, anxiety, or any other clinical conditions. Demographic information was also obtained during this telephone call.

Children in the OCD group were recruited through the Griffith OCD Treatment Program led by the first author (LJF) as part of ongoing research. The purpose of this study and the larger treatment studies were explained to parents at their first contact, and interested parents progressed through assessment, including completing a semistructured screening interview over the phone to address inclusionary and exclusionary criteria. Consenting parents completed the ADIS-P interview to confirm the diagnosis of OCD and any comorbid conditions. Parents and children completed the CY-BOCS to assess OCD severity. Demographic information was obtained, and children completed questionnaire measures at home and returned these at their first treatment sessions. Families of children with a confirmed diagnosis of OCD were invited to participate in an OCD treatment program (see Farrell et al., 2013; Farrell, Waters, \& Zimmer-Gembeck, 2012) and to complete a second assessment session, which included the Ambiguous Situations Task.

Mothers received verbal instructions on how to complete ratings of the ambiguous situations and then the child and mother participants were separated into different rooms to compare ratings. Ambiguous situations were presented to children verbally, in a fixed, randomized order across the emotional categories of the ambiguous situations and in a neutral tone with no indication provided about the potential emotional category of each ambiguous situation. Children were instructed to listen to situations that can happen to children of a similar age to them and to imagine that the event happening in the situation had happened to them. It was explained that they may or may not have experienced these situations before and that there were no right or wrong answers. Clarification was permitted. The examiner recorded open and closed questions about these situations and responses.

Ambiguous situations were presented to mothers in a booklet form in the same fixed order as for children. Mothers were requested to read each situation and to imagine that the event happening in the situation had happened to them and then to answer subsequent questions. It was explained that they may or may not have experienced some of these situations before and that 
there were no right or wrong answers. They were instructed to write down their responses to questions detailed in the response booklet. The mothers then completed the task independently.

\section{RESULTS}

\section{Data Analytic Plan}

Seven $2 \times 3$ mixed analyses of variance (ANOVA) were run to examine both the open and closed child responses. The ANOVAs included Group (OCD and Nonclinical) as the between-subjects variable and Valence (Positive, Neutral, Aversive) as the within-subject variable. Bonferroni corrections were used for analyses that involved multiple comparisons. Partial eta squared $\left(\eta^{2}\right)$ was calculated as a measure of effect size. Children's mean threat interpretation scores for closed and open data are displayed in Tables 1 and 2, respectively. Violations of sphericity required the use of the Huynh-Feldt correction in the reporting of these results.

Hypothesis 1. Analyses showed a significant main effect of Valence on closed thought questions, $F(2,92)=218.46, p \leq .001, \eta^{2}=.826$. Pairwise comparisons showed that children reported fewer threat-based thoughts in the positive-ambiguous situations than both the neutral $(p<.001)$ and aversive $(p<.001)$ situations. Similarly, children reported significantly fewer threat-based thoughts in the neutral-ambiguous situations than the aversive-ambiguous situations $(p<.001)$. The Group main effect, $F(1,46)=1.57, p=.22$, and the Valence $\times$ Group interaction were not significant, $F(2,92)=0.29, p=.75$.

For children's open thoughts, there was a significant main effect of Valence, $F(2,85)=60.80$, $p \leq .001, \eta^{2}=.569$. Post hoc tests using pairwise comparisons revealed that the frequency of positive thoughts in positive-ambiguous situations and threat-related thoughts in aversiveambiguous situations were lower compared with neutral thoughts in neutral-ambiguous situations (both $p<.001$ ). This was expected given that the absence of providing either a clearly positive or threat-related thought would lead to the response being coded as neutral. In comparison, there was no significant difference between positive and aversive situations $(p=1.00)$. The Group main effect, $F(1,46)=1.77, p=.19$, and the Group $\times$ Valence interaction were not significant, $F(2,85)=1.77, p=.179$.

Analyses revealed a main effect of Valence for the closed question on expected feeling, $F(2,79)=63.96, p \leq .001, \eta^{2}=.582$, but not for Group, $F(1,46)=1.53, p=.22$, and the Group $\times$ Valence interaction was also not significant, $F(2,79)=0.28, p=.72$. Post hoc pairwise comparisons showed that children more often correctly identified the expected feeling for positive-ambiguous and aversive-ambiguous situations compared with the neutral-ambiguous (both $p<.001$ ). A chi-square analysis was conducted to assess whether there was any difference between groups in terms endorsement of the expected feeling or another feeling. Results revealed no significant differences between groups, $\chi^{2}(1, N=48)=0.46, p=.50$.

Analyses showed a similar pattern for open responses, with a significant main effect of Valence for feeling, $F(2,86)=69.65, p \leq .001, \eta^{2}=.602$. Post hoc pairwise comparisons showed that overall children were significantly more accurate $(p<.001)$ in identifying the expected feeling in both positive-ambiguous and aversive-ambiguous situations, compared with neutral situations. In addition, there was a significant difference in identification of the expected feeling between aversive-ambiguous and positive-ambiguous situations, with the latter eliciting the greatest accuracy scores $(p<.001)$. Results also showed a significant main effect for Group, $F(1,46)=4.42$, $p=.041, \eta^{2}=.088$, whereby children in the OCD group had lower accuracy in identifying the expected feeling across all situations types compared with the nonclinical group. The Group $\times$ Valence interaction was not significant, $F(2,86)=1.81, p=.172$. A chi-square analysis was conducted to assess whether there was any difference between groups in terms endorsement of the 


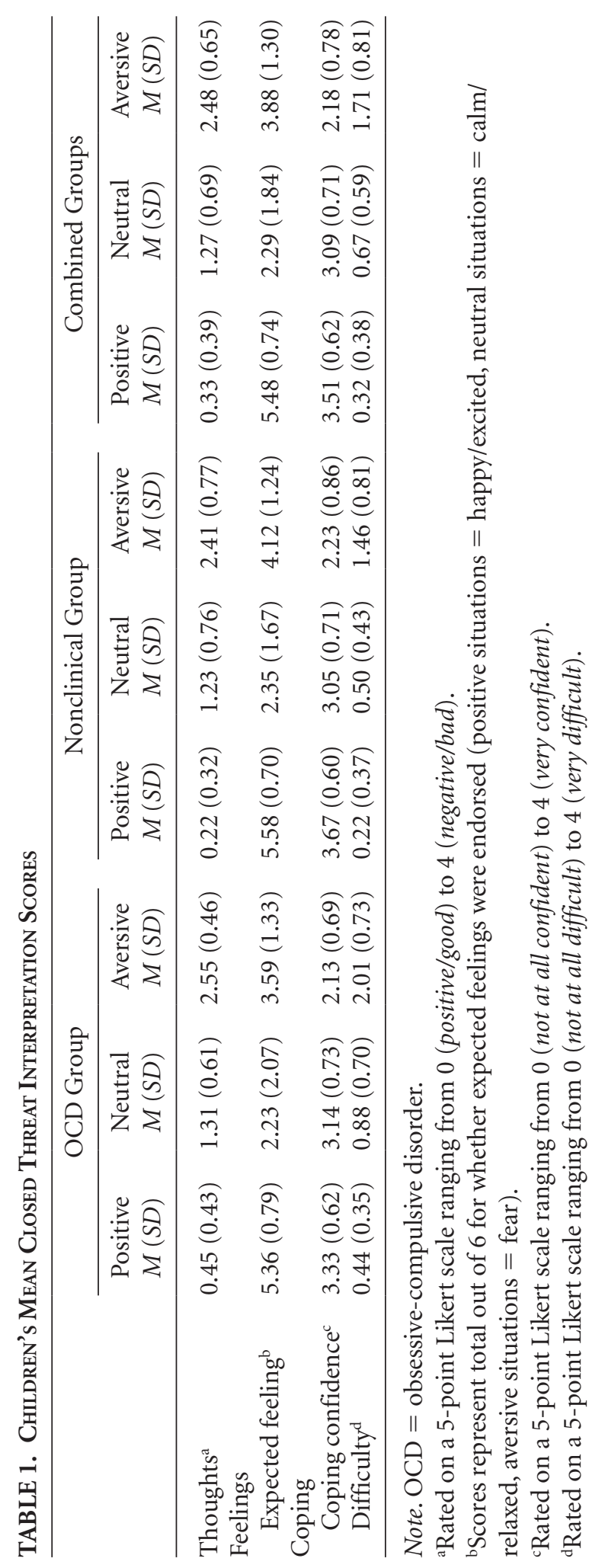




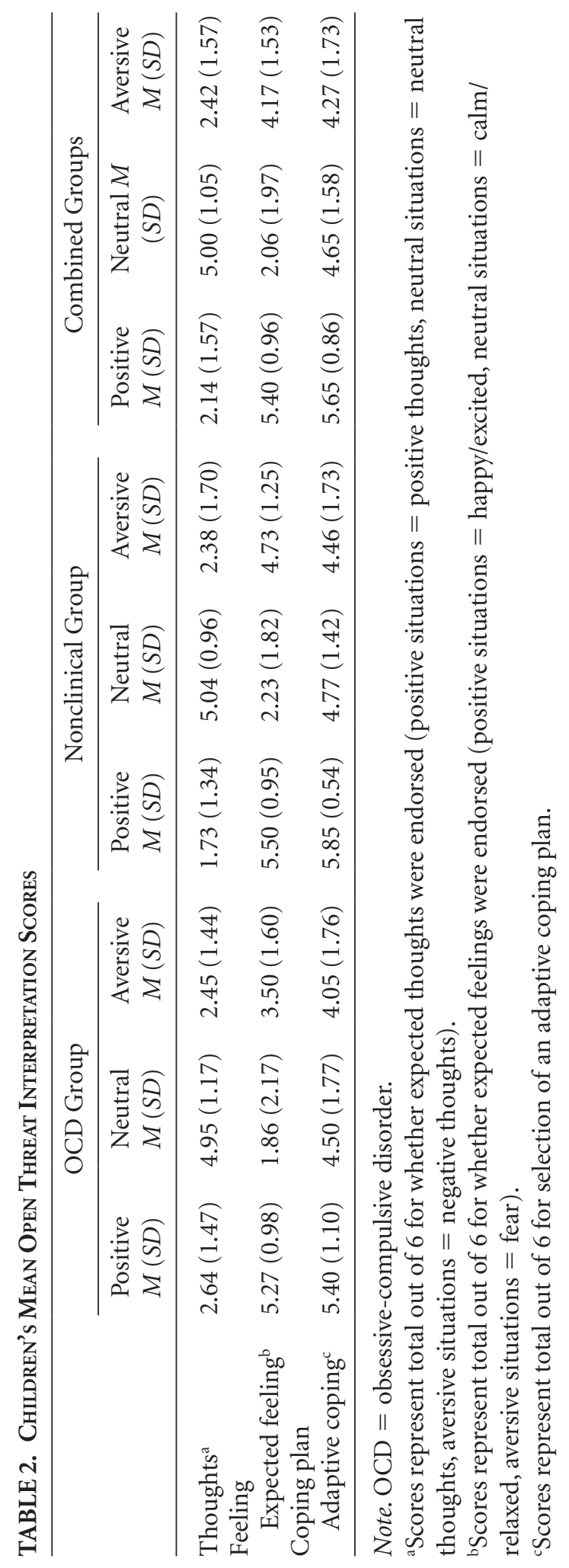


expected feeling or another feeling. Results revealed no significant differences between groups, $\chi^{2}$ $(1, N=48)=1.79, p=.18$.

There was a main effect of Valence, $F(2,74)=90.17, p \leq .001, \eta^{2}=.662$, on appraisals of coping. Post hoc pairwise comparisons showed that children were more confident in their appraisal of coping in positive-ambiguous situations compared with neutral- $(p<.001)$ or aversiveambiguous $(p<.001)$ situations. Similarly, children were more confident in their coping in neutral situations compared with aversive situations $(p<.001)$. There was no significant main effect for Group, $F(1,46)=0.48, p=0.49$, and the Group $\times$ Valence interaction was also not significant, $F(2,74)=2.17, p=.13$.

Analyses showed a main effect of Valence, $F(2,77)=113.39, p \leq .001, \eta^{2}=.771$, for appraisals of difficulty. As expected, children found aversive-ambiguous situations more difficult compared with neutral- and positive-ambiguous situations both at $p<.001$. Similarly, neutral situations were seen to be more difficult than positive situations $(p<.001)$. There was also a main effect for Group, $F(1,46)=8.49, p=.006, \eta^{2}=.156$, which showed that the OCD group reported higher difficulty ratings compared with the nonclinical group. The Group $\times$ Valence interaction was not significant, $F(2,77)=1.46, p=.24$.

For children's open coping plans, there was a main effect of Valence, $F(2,92)=14.15, p \leq .001$, $\eta^{2}=.235$. Pairwise comparisons showed that children received higher scores for adaptive coping plans in positive-ambiguous situations relative to neutral- $(p<.001)$ and aversive-ambiguous situations $(p<.001)$. There was no difference in scores for the neutral and aversive situations $(p=.65)$. The Group main effect, $F(1,46)=1.74, p=.19$, and the Group $\times$ Valence interaction were not significant, $F(2,92)=0.06, p=.94$.

To examine the role of comorbid anxiety symptoms on child threat biases, all analyses were rerun with MASC total scores as a covariate. All of the Valence main effects remained unchanged; however, the Group main effect for open feelings became nonsignificant, $F(1,29)=0.99, p=.33$, as did the Group main effect for difficulty ratings, $F(1,41)=0.32, p=.57$, suggesting that Group differences in endorsing accurate feelings and interpretations of difficulty were likely attributed to concurrent anxiety symptoms, rather than OCD per se.

Hypothesis 2. Mothers' mean threat interpretation scores for both closed and open scores are displayed in Table 3 and Table 4, respectively. Seven $2 \times 3$ mixed factorial ANOVAs were conducted to explore closed and open data, with Group (OCD and Nonclinical) as the between-subjects factor and Valence (Positive, Neutral, Aversive) as the within-subjects factor. In the ANOVAs conducted, Bonferroni corrections were used for analyses that involved multiple comparisons. Given that sphericity was violated, the Huynh-Feldt correction was used in the reporting of these results. Mothers endorsed a wide range of feelings where they did not select the expected feelings across each valence type. Because of the small frequency for these feelings, further analyses could not be conducted.

Analyses showed a main effect of Valence, $F(2,85)=339.52, p \leq .001, \eta^{2}=.881$, for closed questions related to thoughts. Post hoc pairwise comparisons revealed lower threat-based thought scores for positive-ambiguous situations compared with neutral- and aversive-ambiguous situations with both $p s<.001$. Similarly, lower threat-based thought scores for neutral-ambiguous situations were reported, compared with aversive-ambiguous situations $(p<.001)$. There was also a significant main effect for Group, $F(1,46)=5.28, p=.026, \eta^{2}=.103$, whereby mothers of children with OCD reported higher threat-based thinking compared to mothers of nonclinical children overall. The Group $\times$ Valence interaction was not significant, $F(2,85)=1.90, p=.159$.

The analyses of open data for thoughts showed a significant main effect of Valence, $F(2,92)=77.54, p \leq .001, \eta^{2}=.628$. Post hoc pairwise comparisons showed that the number of expected thought type was higher in neutral-ambiguous situations relative to positive-ambiguous situations $(p<.001)$ and aversive-ambiguous situations $(p<.001)$. Similarly, there was a 


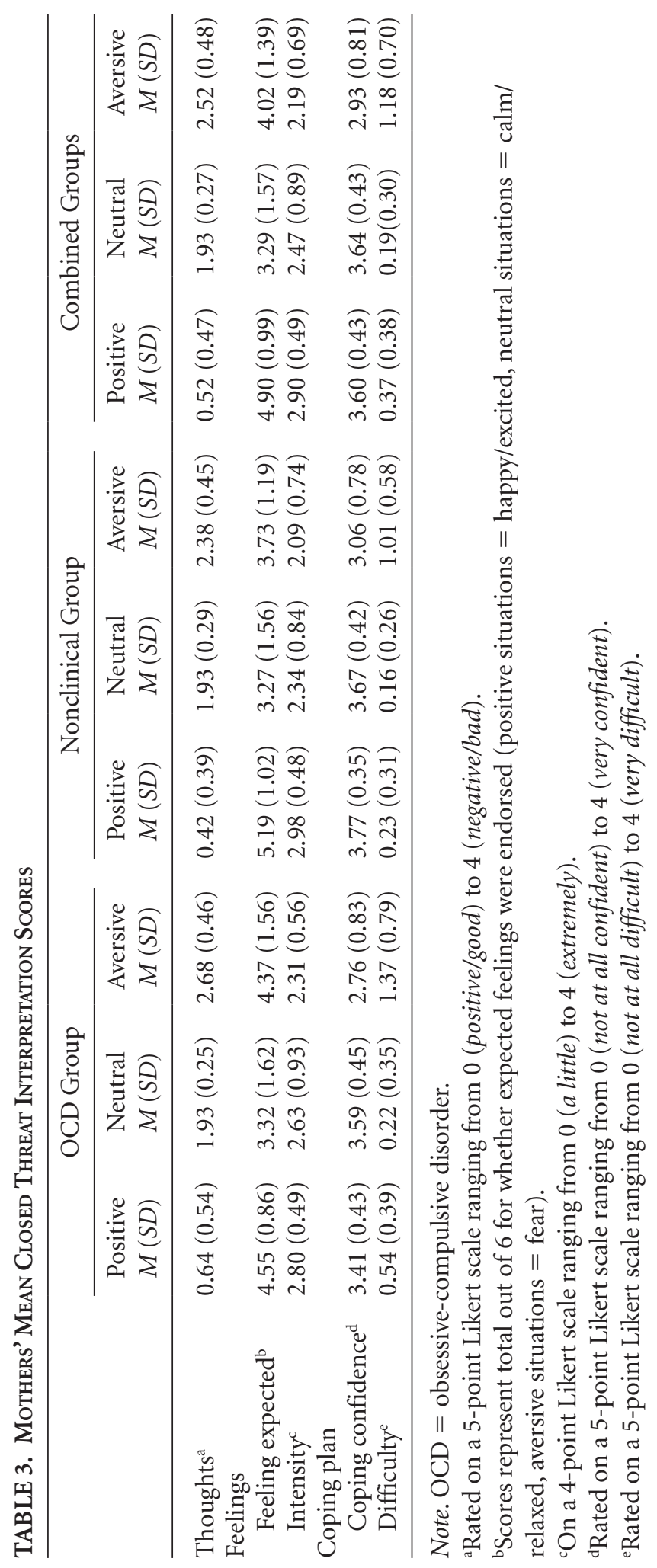




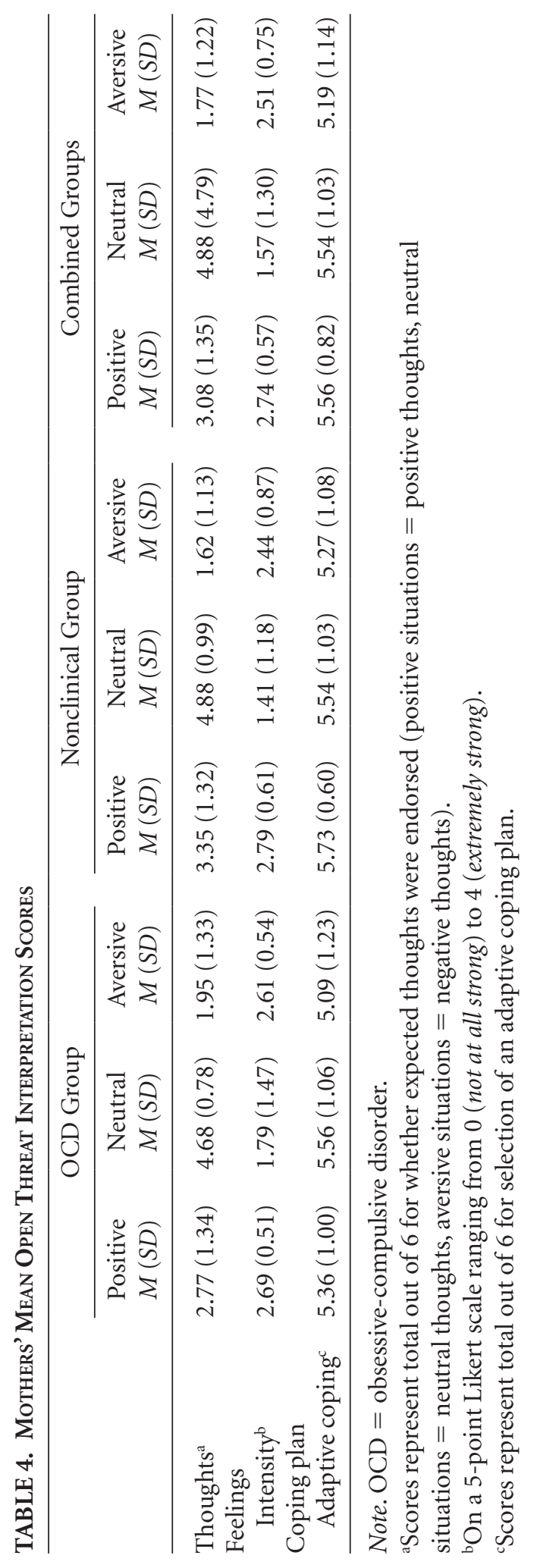


significant difference between positive- and aversive-ambiguous situations $(p<.001)$. There was not a significant main effect for Group, $F(1,46)=0.58, p=.45$, and the Group $\times$ Valence interaction was not significant, $F(2,92)=1.80, p=.17$.

Mothers were more accurate in selecting the expected feeling (closed question) for positiveambiguous situations relative to neutral $(p<.001)$ and aversive-ambiguous situations $(p<.003)$, supported by a main effect of Valence, $F(2,74)=14.21, p \leq .001, \eta^{2}=.236$. There was no difference in the accuracy of identifying the expected feeling in aversive and neutral situations $(p=.137)$. There were no significant main effects for Group, $F(1,46)=.004, p=.95$, and the Group $\times$ Valence interaction was not significant, $F(2,74)=2.35, p=.013$. A chi-square analysis was conducted to assess whether there was any difference between groups in terms endorsement of the expected feeling or another feeling. Results revealed no significant differences between groups, $\chi^{2}(1, N=48)=0.54, p=.46$.

Means and standard errors for mother's open feelings by Group are presented in Figure 1 for each valence: positive, neutral, and aversive situations. Analyses of the open feelings data showed a main effect for Valence, $F(2,92)=53.98, p<.001, \eta^{2}=.540$. There was not a main effect for Group, $F(1,46)=0.62, p=.44$. However, there was a significant Group $\times$ Valence interaction, $F(2,92)=5.29, p=.007, \eta^{2}=.103$. Post hoc comparisons using pairwise comparisons showed that nonclinical mothers more often identified the expected feeling in the positive-ambiguous situations $(p=.001)$, and there were no further differences.

Analyses showed a main effect of Valence, $F(1,64)=49.73, p \leq .001, \eta^{2}=.519$, for appraisals of coping. Pairwise comparisons show that mothers were more confident in their appraisal of coping in positive-ambiguous situations compared with aversive- $(p<.001)$ and neutralambiguous situations compared with aversive situations $(p<.001)$. There was no difference in confidence in coping between neutral- and positive-ambiguous situations $(p=.934)$. The Group main effect, $F(1,46)=3.33, p=.08$, and the Group $\times$ Valence interaction were not significant, $F(1,64)=1.67, p=.20$.

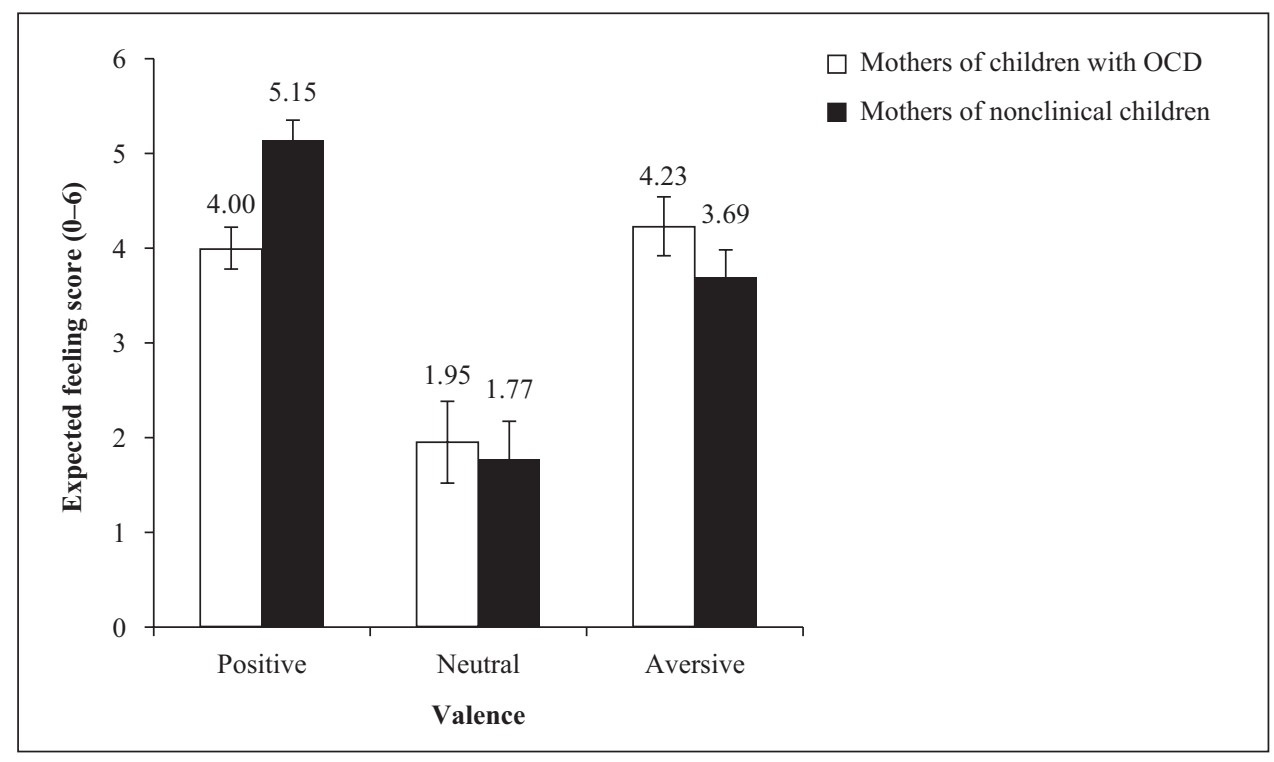

FIGURE 1. Mothers' mean open feelings expected ( + SE bars) by group. OCD = obsessivecompulsive disorder. 
There was a main effect of Valence, $F(2,71)=104.19, p \leq .001, \eta^{2}=.694$, in appraisals of difficulty. In examining the means, mothers reported higher difficulty levels for aversive situations relative to neutral-ambiguous and positive-ambiguous situations. Post hoc pairwise comparisons confirmed these differences were significant with mothers finding aversive-ambiguous situations more difficult compared with neutral- $(p<.001)$ and positive-ambiguous $(p<.001)$ situations. Positive-ambiguous situations also were seen to be more difficult than neutral-ambiguous situations $(p=.001)$. There was also a main effect for Group, $F(1,46)=5.41, p=.024, \eta^{2}=.105$, whereby overall, mothers of children with OCD reported higher difficulty ratings compared with mothers of nonclinical children. The Group $\times$ Valence interaction was not significant, $F(2,71)=$ $2.62, p=.09$.

Analyses of the open data on adaptive scores showed that there was not a significant main effect of Valence, $F(2,92)=2.24, p=.113$, or Group, $F(1,46)=0.98, p=.328$. The Group $\times$ Valence interaction was also not significant, $F(2,92)=0.44, p=.64$. Hence, mothers reported equally adaptive coping plans regardless of the type of situation presented or their group status.

Hypothesis 3. Pearson product-moment correlation coefficients were computed for OCD and nonclinical groups combined to assess the relationships between (a) child and maternal closed threat interpretation scores (i.e., thoughts, coping confidence, and difficulty) for each valence, (b) child anxiety (i.e., MASC totals) and maternal anxiety (i.e., DASS anxiety scores), (c) child anxiety and child closed threat interpretation scores for each valence, and (d) maternal anxiety and maternal closed threat interpretation scores for each valence.

There were no significant correlations between child and maternal threat interpretation scores across valences. There was no significant correlation between child and maternal anxiety scores, $r(44)=.16, p=.29$. There were significant positive correlations between child anxiety and child appraisal of difficulty scores in both neutral situations, $r(44)=.38, p=.01$, and aversive situations, $r(44)=.43, p=.004$. There were no further significant correlations between child anxiety and any of the other threat interpretation scores for each valence.

There were significant positive correlations between maternal anxiety scores and maternal appraisal of difficulty ratings in positive, $r(47)=.40, p=.005$, and aversive situations, $r(47)=.29$, $p=.049$. There were no further significant correlations between maternal anxiety and any of the other threat interpretation scores for each of the valences.

\section{Discussion}

The aim of this research was to investigate general threat interpretation bias in children with OCD relative to nonclinical children and in the mothers of children with OCD relative to mothers of nonclinical children. Results generally supported hypotheses in that there were several significant differences observed between children and between mothers; however, child biases were largely associated with comorbid anxiety symptoms. Furthermore, mothers and children's biases and anxiety were found to be unrelated.

\section{Child Interpretation Bias-Thoughts, Feelings, and Action Plans}

This study identified that children with OCD displayed a stronger threat interpretation bias in terms of perceiving ambiguous situations to be more difficult to manage relative to nonclinical children, when anxiety was not controlled for. This finding is consistent with our hypothesis and prior research that has found differences in perceptions of coping during ambiguous/mildly aversive situations by anxious compared to nonanxious children (e.g., Barrett et al., 1996; Bögels, Snieder, et al., 2003; Waters, Craske, et al., 2008; Waters, Wharton, et al., 2008). Moreover, that this bias extended to ambiguous situations that are neutral or may imbue mildly positive connotations 
in a format in which children were not cued to the potential emotional valence of the ambiguous situations suggests that children with OCD may have a generalized bias for interpreting a range of events as difficult, even ones that nonanxious children might find mildly pleasant.

One explanation for this overall group difference is that perceptions of how difficult situations might be could trigger underlying difficulty in dealing with uncertainty, which has been defined as difficulty with ambiguity, newness, and unpredictable change (OCCWG, 1997) and has been found to be associated with anxiety more generally. In addition, because judgments of difficulty could be influenced by previous experience, elevated difficulty ratings in children with OCD relative to controls may be influenced by prior evidence of themselves experiencing distress in a range of situations (see James, Farrell, \& Zimmer-Gembeck, in press), even though they may not be less confident in coping with these situations, as evidence by no group differences on the confidence response in this study.

Thus, because children with OCD reported greater perceptions of how difficult situations would be but did not differ in coping confidence or in terms of their coping plans, perhaps the bias to interpret events in threat-related terms manifests in overestimations of the threat/ difficulty of situations rather than in underestimations of their coping ability. Moreover, perhaps biased estimations of coping and the extent to which coping plans are maladaptive might be more strongly activated by OCD-specific situations rather than everyday events.

In terms of accuracy in selecting the expected feeling, examination of the open responses revealed that children with OCD were less likely than nonclinical children to provide the expected feeling across situations, although there were no differences between groups in the closed data, when not controlling for anxiety. This suggests a bias in generating rather than recognizing an appropriate feeling in a given situation in children with OCD. Further work is required to better understand the mechanisms underlying biases in emotion recognition/labeling in children with OCD. However, one potential clinical implication is that treatments should encourage the matching of appropriate feelings to situations, which may prevent the generalized experience of distress and increasing impairment, which may in turn contribute to offsetting overestimations of how difficult situations might be.

Although hypothesized, results did not show enhanced threat interpretation bias in children with OCD in terms of their "cognitive" responses. This result is inconsistent with the broader childhood anxiety literature, which suggests increased threat-based thinking in terms of more negative thoughts of situations in anxious children (e.g., Bögels, Snieder, et al., 2003; Bögels \& Zigterman, 2000). The results could also reflect a limitation of the developmental stage of the sample, whereby children may not have fully developed metacognitive abilities or lack the skills to articulate their thoughts, as has been suggested in relation to why obsessions are not as readily identified in children compared with adults (Swedo, Rapoport, Leonard, Lenane, \& Cheslow, 1989). Alternatively, biases in threat-based thinking may be specific to OCD-related situations.

The finding that group differences on difficulty ratings and accuracy of identifying expected feelings became nonsignificant once anxiety was controlled for suggests that children's interpretation biases might be more strongly associated with comorbid anxiety symptomatology than OCD per se. This is an important finding that highlights the need for further investigation to tease apart the more precise nature of interpretation biases in childhood OCD, taking into consideration comorbid anxiety disorders. Another explanation for the current finding, however, is that children's responses to the MASC anxiety self-report may also be inflated as a function of OCD impairment in addition to anxiety comorbidity. Given that OCD results in significant impairment at school as well as in academic performance, family, and peer relationships (see James et al., in press), it is likely that children's responses to MASC items also somewhat reflects OCD impairment in addition to being an index of concurrent anxiety. Given that anxiety comorbidity is indeed the norm rather than the exception among children with OCD; however, these findings 
highlight that current treatments might be improved by incorporating anxiety management techniques, specifically focused on cognitive restructuring aimed at reducing overestimation of threat and intolerance of uncertainty among children with OCD.

\section{Mother Interpretation Bias-Thoughts, Feelings, and Action Plans}

Mothers of children with OCD reported more threat-based thoughts and greater perceptions of difficulty across ambiguous situations that could be considered mildly aversive, neutral, and mildly positive, even though mothers were not cued to the potential emotional valence of these situations. They were also less accurate in identifying the expected feeling in ambiguous situations that may be perceived as mildly positive.

Although no previous research of this type has been conducted with mothers of children with OCD, threat interpretation bias of ambiguous and mildly aversive situations has been identified in studies of mothers of anxious children without OCD (e.g., Creswell et al., 2005). What was unexpected from these results is that higher ratings for difficulty and negative thinking were evident across all situations in mothers of children with OCD, compared to nonclinical mothers. The current findings suggest that the mothers of children with OCD may have a broad-based threat bias to interpret situations in general as threatening and difficult. One explanation for these results is that mothers' interpretation style is a risk factor for children's interpretation style. Although correlations between child and mother bias were not significant, perhaps mother's threat interpretations contribute indirectly to a context of enhanced threat salience, consistent with an indirect pathway of learning (see Muris \& Field, 2010). Another explanation may be that raising a child with OCD increases the mother's actual or perceived experience of threat and difficulty in managing a wide range of situations, including potentially positive ones. Thus, she may become hyper vigilant for potential threats to her child or within their environment or see situations as less positive given ongoing and daily negative strain, which in turn influences the development of threat-based biases concerning herself (Storch et al., 2009). The findings of this study broadly accord with child anxiety literature which purports that the relationship between anxious children and parents is likely bidirectional with both influencing each other (Ginsburg \& Schlossberg, 2002; Hudson, Doyle, \& Gar, 2009).

\section{Associations Within and Between Child and Mother Variables}

This study did not find significant correlations between child and maternal threat interpretation scores. The fact that there was no significant relationship between child and maternal negative thoughts about the situations is disparate with Creswell et al. (2005) who found a relationship between threat interpretation bias (in terms of negative judgments about situations) in anxious children and their mothers. Although child and maternal threat interpretations of general daily experiences appear not be associated - it may be that there are associations between parental and child biases specific to OCD-related situations, particularly given the high degree of family involvement and accommodation associated with childhood OCD (see James et al., in press). In accord, Creswell et al. (2006) suggested that parent cognitions might be a more proximal index of transmission than general anxiety in children with broad-based (non-OCD) anxiety disorders. Therefore, because of extensive time focused on OCD in families with a child experiencing OCD because of family accommodation and overinvolvement, perhaps child and parental biases regarding OCD-specific situations would be more strongly related.

There are several strengths and limitations of this research. A particular strength of this study is that it included a clinical group of children with primary OCD and a comparison group of nonclinical children. Furthermore, the study used a previously published methodological approach in 
measuring threat interpretation bias by use of the ambiguous situations paradigm. The inclusion of differing situations that varied in potential for imbuing emotional connotations improved on our current understanding of responses to ambiguity.

Despite these strengths, there are several limitations. First, as Creswell et al. (2006) aptly described, it is unlikely that within a two-parent family (which most participants in this study come from) that only mothers have influence over the development and reinforcement of children's threat interpretation bias. Therefore, that lack of inclusion of fathers is a clear, albeit not uncommon, inadequacy of this study. A recent study by Bögels, Stevens, and Majdandžić (2011) with children with varying degrees of social anxiety, using ambiguous social situations in which both parents either reacted in a socially anxious or socially confident way showed differential influences. Hence, the need for a greater understanding of the role of fathers in childhood anxiety is warranted, and this includes fathers of children with OCD.

Results reported in this study were generated in response to hypothetical ambiguous situations rather than real events and that because of the cross-sectional nature of this study, it does not provide causal evidence. Furthermore, single-item Likert response scales may have inadequate reliability and validity. Whether responses to hypothetical situations are comparable to children's reactions in real life events is difficult to know (Voncken, Bögels, \& de Vries, 2003). Essentially, the study provides a measure of perceptions of situations and responses and not actual responses and coping. Hence, it is likely there are differences between the groups that the tasks used in this study did not detect. However, the ambiguous situations paradigm is a well-established approach for assessing threat interpretation bias used extensively in both adult and child anxiety disorder literature. The inclusion of additional clinical groups (e.g., other anxiety disorders and externalizing disorders) would be helpful in future studies to detect threat interpretation biases and family processes that are unique to OCD. Indeed, given that the study did not include an anxious sample without OCD and considering the high rate of comorbidity of other anxiety disorders in the clinical group, the next logical step will be to investigate whether the findings are specific to OCD or not.

The study failed to elicit specific thoughts about the situation, which may have been more sensitive to detecting threat interpretation bias. This may suggest a problem with the way the question was worded (i.e., "What would you think in this situation?"). Researchers such as Barrett et al. (1996) and Chorpita et al. (1996) asked, "What do you think is happening," which is argued by Bögels and Zigterman (2000) to measure threat interpretation but not dysfunctional cognitions. Hence, they asked, "What do you think of this situation?" Further consideration of the best way to elicit information on thoughts may be warranted perhaps through more extensive piloting.

In recognizing the exploratory nature of this study as well as the limitations outlined, results provide preliminary evidence of interpretation bias in both children with OCD and their mothers in terms of appraisals of difficulty and accurate emotions in various ambiguous situations. These findings support the need for future research into family factors associated with childhood OCD as well as further attention as to how clinicians can best work with families in treating childhood OCD. Replication and extension of this research may contribute to the advancement of developmentally sensitive cognitive models of OCD, which may lead to further improvements in treatment.

\section{NoTeS}

1. Full details on the Ambiguous Situations Task, including all scenarios descriptions as well as child and parent response forms are available from the lead author (LJF) upon request.

2. Data on the piloting of the scenarios are available from the lead author upon request. 
3. Coding procedures. (1.) Open thoughts were rated for valence (positive, negative, neutral) using the definitions of Cacioppo and Petty (1981) and following the methodology of Bögels, van Dongen, et al. (2003). Thoughts were coded as positive statements if they mentioned specific desirable or positive associations and/or positive affect. For example, "that sounds like fun," and "I am thinking how excited I am." Thoughts were coded as neutral if they expressed no affect and/or did not mention either a positive or negative association. For example, "nothing," and "I wonder where he is?" Thoughts were coded as negative if they mentioned specific undesirable or negative associations and/or negative affect. For example, "there might be a something bad in there," "I am nervous." (2.) Open feelings were coded into categories similar to those described in Bögels, van Dongen, et al. (2003) and Waters, Wharton, et al. (2008). Joy and curious were added given the introduction of positive and neutral situations, which were not included in previous research. Coders assigned one of the following feelings categories to each feeling reported by the participants: joy, sad, angry, curious, calm/relaxed, shy, guilty, fear, responsible, lonely, did not know/unsure, other. Second, similar to the procedure described in Waters, Wharton, et al. (2008), feelings were coded as a total out of 6 of the number of expected feelings across the six situations for each valence as described for the closed feelings responses. In positive situations, the expected feelings type was joy; in neutral situations, the expected feeling was calm/relaxed; and in aversive situations, the expected feeling was fear. Only the primary feeling was used in the further analysis because most children and mothers provided only one feeling for most situations. (3.) Coping plans were coded similarly to Bögels, van Dongen, et al. (2003) and Barrett et al. (1996). However, particular attention was paid to valence of situation in coding responses because the inclusion of positive and neutral situations in this study necessitated consideration of whether an action was actually required or not. If an action was suggested, how relevant and adaptive it was in that particular situation was considered. Responses were first coded into type of coping: (a) adaptive/coping, (b) adaptive/neutral, (c) maladaptive/avoidant, (d) maladaptive/aggressive, and (e) unclassifiable. Coping data were reduced by counting these for each valence type for both adaptive and maladaptive responses. Hence, each participant derived a score out of 6 for adaptive coping and a score out of 6 for maladaptive coping by situation type. To attain an "adaptive coping," the total maladaptive scores were deducted from the adaptive scores so that each participant had a score between -6 to +6 , with positive scores indicating more adaptive coping, with $6+$ the highest possible score.

\section{REFERENCES}

Barrett, P. M., Rapee, R. M., Dadds, M. M., \& Ryan, S. M. (1996). Family enhancement of cognitive style in anxious and aggressive children. Journal of Abnormal Child Psychology, 24(2), 187-203. http://dx.doi .org/10.1007/BF01441484

Beck, A. T., \& Emery, G. (1985). Anxiety disorders and phobias: A cognitive perspective. New York, NY: Basic Books. Bögels, S., Snieder, N., \& Kindt, M. (2003). Specificity of dysfunctional thinking in children with symptoms of social anxiety, separation anxiety and generalised anxiety. Behaviour Change, 20(3), 160-169.

Bögels, S., Stevens, J., \& Majdandžić, M. (2011). Parenting and social anxiety: Fathers' versus mothers' influence on their children's anxiety in ambiguous social situations. Journal of Child Psychology and Psychiatry, 52(5), 599-606. http://dx.doi.org/10.1111/j.1469-7610.2010.02345.x

Bögels, S., van Dongen, L., \& Muris, P. (2003). Family influences on dysfunctional thinking in anxious children. Infant and Child Development, 12(3), 243-252. http://dx.doi.org/10.1002/icd.288

Bögels, S., \& Zigterman, D. (2000). Dysfunctional cognitions in children with social phobia, separation anxiety disorder, and generalised anxiety disorder. Journal of Abnormal Child Psychology, 28(2), 205-211. http://dx.doi.org/10.1023/A:1005179032470

Bolton, D., Williams, T., Perrin, S., Atkinson, L., Gallop, C., Waite, P., \& Salkovskis, P. (2011). Randomized controlled trial of full and brief cognitive-behaviour therapy and wait-list for paediatric obsessivecompulsive disorder. Journal of Child Psychology and Psychiatry, 52(12), 1269-1278. http://dx.doi .org/10.1111/j.1469-7610.2011.02419.x 
Brown, T. A., Chorpita, B. F., Korotitsch, W., \& Barlow, D. H. (1997). Psychometric properties of the Depression Anxiety Stress Scales (DASS) in clinical samples. Behaviour Research and Therapy, 35(1), 79-89. http://dx.doi.org/10.1016/s0005-7967(96)00068-x

Buhlmann, U., McNally, R. J., Wilhelm, S., \& Florin, I. (2002). Selective processing of emotional information in body dysmorphic disorder. Journal of Anxiety Disorders, 16(3), 289-298. http://dx.doi.org/10.1016/ S0887-6185(02)00100-7

Butler, G., \& Mathews, A. (1983). Cognitive processes in anxiety. Advances in Behaviour Research and Therapy, 5(1), 51-62. http://dx.doi.org/10.1016/0146-6402(83)90015-2

Cacioppo, J. T., \& Petty, R. E. (1981). Social psychological procedures for cognitive response assessment: The thought-listing technique. In T. V. Merluzzi, C. R. Glass, \& M. Genest (Eds.), Cognitive assessment (pp. 309-342). New York, NY: Guilford Press.

Carr, A. T. (1974). Compulsive neurosis: A review of the literature. Psychological Bulletin, 81(5), 311-318.

Chorpita, B. F., Albano, A. M., \& Barlow, D. H. (1996). Cognitive processing in children: Relation to anxiety and family influences. Journal of Clinical Child Psychology, 25(2), 170-176. http://dx.doi.org/10.1207/ s15374424jccp2502_5

Clark, D. A., \& Purdon, C. (1993). New perspectives for a cognitive theory of obsessions. Australian Psychologist, 28(3), 161-167. http://dx.doi.org/10.1080/00050069308258896

Creswell, C., \& O'Connor, T. G. (2006). Anxious cognitions in children: An exploration of associations and mediators. British Journal of Developmental Psychology, 24, 761-766. http://dx.doi .org/10.1348/026151005X70418

Creswell, C., O'Connor, T. G., \& Brewin, C. R. (2006). A longitudinal investigation of maternal and child 'anxious cognitions.' Cognitive Therapy and Research, 30, 135-147. http://dx.doi.org/10.1007/ s10608-006-9021-1

Creswell, C., Schniering, C. A., \& Rapee, R. M. (2005). Threat interpretation in anxious children and their mothers: Comparison with nonclinical children and the effects of treatment. Behaviour Research and Therapy, 43, 1375-1381. http://dx.doi.org/10.1016/j.brat.2004.10.009

Farrell, L. J., Waters, A. M., Boschen, M. J., Hattingh, L., McConnell, H., Milliner, E. L., . . Storch, E. A. (2013). Difficult-to-treat pediatric obsessive-compulsive disorder: Feasibility and preliminary results of a randomized pilot trial of D-Cycloserine-augmented behavior therapy. Depression and Anxiety, 30(8), 723-731. http://dx.doi.org/10.1002/da.22132

Farrell, L. J., Waters, A. M., \& Zimmer-Gembeck, M. J. (2012). Cognitive biases and obsessive-compulsive symptoms in children: Examining the role of maternal cognitive bias and child age. Behavior Therapy, 43(3), 593-605. http://dx.doi.org/10.1016/j.beth.2011.10.003

Foa, E. B., \& Kozak, M. J. (1986). Emotional processing of fear: Exposure to corrective information. Psychological Bulletin, 99(1), 20-35.

Frost, R. O., \& Steketee, G. (Eds.). (2002). Cognitive approaches to obsessions and compulsions: Theory, assessment, and treatment. Oxford, United Kingdom: Elsevier Science.

Ginsburg, G. S., \& Schlossberg, M. C. (2002). Family-based treatment of childhood anxiety disorders. International Review of Psychiatry, 14(2), 143-154. http://dx.doi.org/10.1080/09540260220132662

Guidano, V. F., \& Liotti, G. (1983). Cognitive processes and emotional disorders. New York, NY: Guilford Press.

Hudson, J. L., Doyle, A. M., \& Gar, N. (2009). Child and maternal influence on parenting behavior in clinically anxious children. Journal of Clinical Child \& Adolescent Psychology, 38(2), 256-262. http://dx.doi .org/10.1080/15374410802698438

James, S. C., Farrell, L. J., \& Zimmer-Gembeck, M. J. (in press). Description and prevalence of OCD in children and adolescents. In J. Abramowitz, D. McKay, \& E. Storch (Eds.), Handbook of obsessive-compulsive disorder across the lifespan. Hoboken, NJ: Wiley.

Kuckertz, J. M., Amir, N., Tobin, A. C., \& Najmi, S. (2013). Interpretation of ambiguity in individuals with obsessive-compulsive symptoms. Cognitive Therapy and Research, 37(2), 232-241. http://dx.doi .org/10.1007/s10608-012-9478-z 
Lovibond, S. H., \& Lovibond, P. F. (1995). Manual for the Depression Anxiety Stress Scales (2nd ed.). Sydney, Australia: Psychology Foundation of Australia.

March, J. (1997). Multidimensional Anxiety Scale for Children: Technical Manual. New York, NY: MultiHealth Systems.

March, J., Parker, J., Sullivan, K., Stallings, P., \& Conners, K. (1999). The Multidimensional Anxiety Scale for Children (MASC): Factor structure, reliability, and validity. Journal of the American Academy of Child and Adolescent Psychiatry, 36(4), 554-565.

McFall, M. E., \& Wollersheim, J. P. (1979). Obsessive-compulsive neurosis: A cognitive-behavioral formulation and approach to treatment. Cognitive Therapy and Research, 3(4), 333-348. http://dx.doi .org/10.1007/BF01184447

Micco, J. A., \& Ehrenreich, J. T. (2008). Children's interpretation and avoidant response biases in response to non-salient and salient situations: Relationships with mothers' threat perception and coping expectations. Journal of Anxiety Disorders, 22(3), 371-385. http://dx.doi.org/10.1016/j.janxdis.2007.03.009

Muris, P., \& Field, A. P. (2010). The role of verbal threat information in the development of childhood fear. "Beware the Jabberwock!" Clinical Child and Family Psychology Review, 13(2), 129-150. http://dx.doi .org/10.1007/s10567-010-0064-1

Muris, P., Rapee, R. M., Meesters, C., Schouten, E., \& Geers, M. (2003). Threat perception abnormalities in children: The role of anxiety disorders symptoms, chronic anxiety, and state anxiety. Journal of Anxiety Disorders, 17(3), 271-287. http://dx.doi.org/10.1016/s0887-6185(02)00199-8

Nauta, M. H., Scholing, A., Rapee, R. M., Abbott, M., Spence, S. H., \& Waters, A. (2004). A parent-report measure of children's anxiety: Psychometric properties and comparison with child-report in a clinic and normal sample. Behaviour Research and Therapy, 42, 813-839. http://dx.doi.org/10.1016/ S0005-7967(03)00200-6

ObsessiveCompulsiveCognitionsWorking Group.(1997).Cognitiveassessmentofobsessive-compulsivedisorder. Behaviour Research and Therapy, 35(7), 667-681. http://dx.doi.org/10.1016/s0005-7967(97)00017-x

Obsessive Compulsive Cognitions Working Group. (2001). Development and initial validation of the obsessive beliefs questionnaire and the interpretation of intrusions inventory. Behaviour Research and Therapy, 39(8), 987-1006.

Obsessive Compulsive Cognitions Working Group. (2003). Psychometric validation of the Obsessive Beliefs Questionnaire and the Interpretation of Intrusions Inventory: Part 1. Behaviour Research and Therapy, $41,863-878$.

Obsessive Compulsive Cognitions Working Group. (2005). Psychometric validation of the obsessive belief questionnaire and interpretation of intrusions inventory-Part 2: Factor analyses and testing of a brief version. Behaviour Research and Therapy, 43(11), 1527-1542.

Page, A. C., Hooke, G. R., \& Morrison, D. L. (2007). Psychometric properties of the Depression Anxiety Stress Scales (DASS) in depressed clinical samples. British Journal of Clinical Psychology, 46(3), 283-297. http://dx.doi.org/10.1348/014466506x158996

Pediatric OCD Treatment Study Team. (2004). Cognitive-behavior therapy, sertraline, and their combination for children and adolescents with obsessive-compulsive disorder: The Pediatric OCD Treatment Study (POTS) randomized controlled trial. Journal of the American Medical Association, 292, 1969-1976.

Rachman, S. (1997). A cognitive theory of obsessions. Behaviour Research and Therapy, 35(9), 793-802. http://dx.doi.org/10.1016/S0005-7967(97)00040-5

Rachman, S. (1998). A cognitive theory of obsessions: Elaborations. Behaviour Research and Therapy, 36(4), 385-401. http://dx.doi.org/10.1016/S0005-7967(97)10041-9

Rapee, R. M., Schniering, C. A., \& Hudson, J. L. (2009). Anxiety disorders during childhood and adolescence: Origins and treatment. Annual Review of Clinical Psychology, 5, 311-341.

Rector, N. A., Cassin, S. E., Richter, M. A., \& Burroughs, E. (2009). Obsessive beliefs in first-degree relatives of patients with OCD: A test of the cognitive vulnerability model. Journal of Anxiety Disorders, 23(1), 145-149. http://dx.doi.org/10.1016/j.janxdis.2008.06.001 
Reynolds, S., \& Reeves, J. (2008). Do cognitive models of obsessive compulsive disorder apply to children and adolescents? Behavioural and Cognitive Psychotherapy, 36(4), 463-471. http://dx.doi.org/10.1017/ S1352465808004463

Salkovskis, P. M. (1985). Obsessional-compulsive problems: A cognitive-behavioural analysis. Behaviour Research and Therapy, 23(5), 571-583. http://dx.doi.org/10.1016/0005-7967(85)90105-6

Scahill, L., Riddle, M. A., McSwiggin-Hardin, M. T., Ort, S. I., King, R. A., Goodman, W. K., . . Leckman, J. F. (1997). The Children's Yale-Brown Obsessive-Compulsive Scale: Reliability and validity. Journal of the American Academy of Child and Adolescent Psychiatry, 36, 844-852.

Silverman, W. K., \& Albano, A. M. (1996). The Anxiety Disorders Interview Schedule for DSM-IV: Child and parent versions. San Antonio, TX: The Psychological Corporation.

Silverman, W. K., Saavedra, L. M., \& Pina, A. A. (2001). Test-retest reliability of anxiety symptoms and diagnosis with the Anxiety Disorders Interview Schedule for DSM-IV: Child and parent versions. Journal of the American Academy of Child and Adolescent Psychiatry, 40, 937-944. http://dx.doi.org/10.1097 \%2F00004583-200108000-00016

Spence, S. H. (1998). A measure of anxiety symptoms among children. Behaviour Research and Therapy, 36, $545-566$.

Steketee, G., \& Frost, R. O. (1994). Measurement of risk-taking in obsessive-compulsive disorder. Behavioural and Cognitive Psychotherapy, 22(4), 287-298. http://dx.doi.org/10.1017/S1352465800013175

Steketee, G., Frost, R. O., \& Cohen, I. (1998). Beliefs in obsessive-compulsive disorder. Journal of Anxiety Disorders, 12(6), 525-537. http://dx.doi.org/10.1016/S0887-6185(98)00030-9

Storch, E. A., Lehmkuhl, H., Pence, S., Jr., Geffken, G., Ricketts, E., Storch, J., \& Murphy, T. K. (2009). Parental experiences of having a child with obsessive-compulsive disorder: Associations with clinical characteristics and caregiver adjustment. Journal of Child and Family Studies, 18(3), 249-258. http://dx.doi .org/10.1007/s10826-008-9225-y

Suarez, L., \& Bell-Dolan, D. (2001). The relationship of child worry to cognitive biases: Threat interpretation and likelihood of event occurrence. Behavior Therapy, 32(3), 425-442. http://dx.doi.org/10.1016/ S0005-7894(01)80029-0

Swedo, S. E., Rapoport, J. L., Leonard, H., Lenane, M., \& Cheslow, D. (1989). Obsessive-compulsive disorder in children and adolescents: Clinical phenomenology of 70 consecutive cases. Archives of General Psychiatry, 46(4), 335-341. http://dx.doi.org/10.1001/archpsyc.1989.01810040041007

Taylor, S., Abramowitz, J. S., \& McKay, D. (2007). Cognitive-behavioral models of obsessive-compulsive disorder. In M. Anthony, C. Purdon, \& L. J. Summerfeldt (Eds.), Psychological treatment of obsessivecompulsive disorder: Fundamentals and beyond (pp. 9-29). Washington, DC: American Psychological Association.

Voncken, M. J., Bögels, S., \& de Vries, K. (2003). Interpretation and judgemental biases in social phobia. Behaviour Research and Therapy, 41(12), 1481-1488. http://dx.doi.org/10.1016/S0005-7967(03)00143-8

Waters, A., Craske, M. G., Bergman, R. L., \& Treanor, M. (2008). Threat interpretation bias as a vulnerability factor in childhood anxiety disorders. Behaviour Research and Therapy, 46(1), 39-47. http://dx.doi .org/10.1016/j.brat.2007.10.002

Waters, A., Wharton, T. A., Zimmer-Gembeck, M. J., \& Craske, M. G. (2008). Threat-based cognitive biases in anxious children: Comparison with non-anxious children before and after cognitive behavioural treatment. Behaviour Research and Therapy, 46(3), 358-374.

Wilhelm, S., \& Steketee, G. S. (2006). Cognitive therapy for obsessive compulsive disorder: A guide for professionals. Oakland, CA: New Harbinger Publications.

Wilhelm, S., Steketee, G., Fama, J. M., Buhlmann, U., Teachman, B. A., \& Golan, E. (2009). Modular cognitive therapy for obsessive-compulsive disorder: A wait-list controlled trial. Journal of Cognitive Psychotherapy, 23(4), 294-305.

Williams, J. M. G., Watts, F. N., MacLeod, C., \& Mathews, A. (1997). Cognitive psychology and emotional disorders (2nd ed.). Chichester, United Kingdom: Wiley. 
Williams, T. I., Salkovskis, P. M., Forrester, L., Turner, S., White, H., \& Allsopp, M. A. (2010). A randomised controlled trial of cognitive behavioural treatment for obsessive compulsive disorder in children and adolescents. European Child \& Adolescent Psychiatry, 19(5), 449-456. http://dx.doi.org/10.1007/ s00787-009-0077-9

Woods, C. M., Frost, R. O., \& Steketee, G. (2002). Obsessive compulsive (OC) symptoms and subjective severity, probability, and coping ability estimations of future negative events. Clinical Psychology \& Psychotherapy, 9(2), 104-111. http://dx.doi.org/10.1002/cpp.304

Correspondence regarding this article should be directed to Lara J. Farrell, PhD, Griffith University, Gold Coast Campus, Griffith Health Centre, G40_7.35. Parklands Drive, Southport QLD, 4215. E-mail: L.Farrell@griffith .edu.au 